\title{
Distribuição do Elemento Transponível Impala em Isolados de Fusarium oxysporum Patogênicos e Não-Patogênicos ao Feijoeiro
}

\author{
Michele G. S. Zanotti', Jildete K. Santos ${ }^{1}$, Kledna C. P. Reis' ${ }^{1}$ Elza F. Araújo ${ }^{1}$, \\ Onkar Dev Dhingra ${ }^{2}$ \& Marisa V. Queiroz ${ }^{1}$ \\ ${ }^{1}$ Departamento de Microbiologia; ${ }^{2}$ Fitopatologia, Universidade Federal de Viçosa, CEP 36571-000, Viçosa, MG, \\ fax: (031) 3899-2573, e-mail: mvqueiro@ufv.br
}

(Aceito para publicação em 17/03/2005)

Autor para correspondência: Marisa Vieira de Queiroz

ZANOTTI, M.G.S., SANTOS, J.K., REIS, K.C.P., ARAÚJO, E.F., DHINGRA, O.D. \& QUEIROZ, M.V. Distribuição do elemento transponível impala em isolados de Fusarium oxysporum patogênicos e não-patogênicos ao feijoeiro. Fitopatologia Brasileira 30:244-249. 2005.

\section{RESUMO}

A variabilidade genética de 20 isolados de Fusarium oxysporum, nove não-patogênicos e 11 patogênicos ao feijoeiro (Phaseouls vulgaris), foi determinada com base na distribuição do elemento transponível impala. A presença de impala das subfamílias D e E foi determinada por experimentos de PCR, empregando oligonucleotídeos específicos para cada subfamília. Foi observada a presença de representantes das duas subfamílias na maioria dos isolados, sugerindo, portanto, que impala é um antigo componente do genoma de F. oxysporum f. sp. phaseoli. A hibridização do DNA total de cada isolado, clivado com a enzima EcoRI, com um fragmento do elemento impala da subfamíla E, mostrou uma variação nos padrões de bandas dos isolados não-patogênicos, indicando a possível atividade desses elementos. No entanto, no caso dos isolados patogênicos, foram observados padrões de bandas mais homogêneas e alguns isolados apresentaram o mesmo perfil de bandas, indicando que se trata de cópias de impala que, possivelmente, não são mais capazes de sofrer transposição. Estas cópias inativas são excelentes marcadores genéticos. Um dos isolados patogênicos, Fus4, não apresentou cópias endógenas de impala, o que torna esse isolado um candidato para experimentos de mutagênese insercional usando o vetor pNI160, que possui o elemento impala ativo interrompendo o gene nia $\mathrm{D}$, que codifica a enzima nitrato redutase.

Palavras-chave adicionais: transposon, murcha de feijoeiro, PCR, variabilidade genética, patogenicidade.

\begin{abstract}
Distribution of the transposable element impala in Fusarium oxysporum isolates pathogenic and nonpathogenic to common bean

The genetic variability of 20 isolates of Fusarium oxysporum, nine nonpathogenic and 11 causing common bean (Phaseouls vulgaris) wilt, was analyzed on the basis of the distribution of the transposable element impala. The presence of transposable elements belonging to subfamilies D and E of impala was determined through polymerase chain reaction (PCR) using specific primers for each subfamily. The presence of members of the two subfamilies was observed in most of the isolates, suggesting that it is an old component in the F. oxysporum f. sp. phaseoli genoma. Hybridization of total DNA of each isolate, digested with EcoRI, with impala fragments of subfamily E produced a highly variable band pattern in the nonpathogenic isolates, indicating the possible activity of these elements. On the other hand, in pathogenic isolates, the band patterns were more homogeneous and some isolates showed very similar patterns, indicating that these impala copies have lost their capacity to transpose. These inactive copies are suitable as genetic markers. Among the pathogenic isolates, endogenous copies of impala were not detected in Fus4; therefore, this isolate could be used in experiments of insertional mutagenesis with the pNI160 plasmid, which harbors the active W impala element disrupting the niaD (nitrate reductase) gene.

Additional keywords: transposon, bean wilt, PCR, genetic variability, pathogenicity.
\end{abstract}

\section{INTRODUÇÃO}

Os fungos do gênero Fusarium destacam-se entre os mais importantes agentes causais de doenças na cultura do feijoeiro (Phaseolus vulgaris L.) (Woo et al., 1996). A espécie Fusarium oxysporum foi colocada na seção (grupo) Elegans por Wollenweber \& Reinking (1935) junto com outras nove espécies, no entanto, considerável variação morfológica e fisiológica ocorre nesta espécie devido à influência ambiental (Gordon \& Martyn, 1997). Por isso, Snyder \& Hansen (1940) agruparam na seção Elegans uma única espécie: F. oxysporum. Esta espécie é caracterizada por ser haplóide, sem estádio sexual definido, podendo ser patogênica ou não (Kistler, 1997). Isolados patogênicos de $F$. oxysporum possuem especificidade em relação à planta hospedeira, podendo ser subdivididos em formae speciales, baseado na capacidade de causar doença em um hospedeiro em particular ou grupos de hospedeiros, e em raças fisiológicas, baseado nas diferenças de resistência à doença observada entre os diferentes cultivares (Alves-Santos et al., 1999). As linhagens não-patogênicas 
são capazes de persistir por meio da colonização assintomática nas raízes da planta hospedeira e por crescimento saprofítico na matéria orgânica morta (Gordon \& Okamoto, 1992).

Como F. oxysporum não tem estádio sexual conhecido, a variabilidade genética é, em parte, gerada por parassexualidade, onde recombinantes haplóides são recuperados a partir de heterocários (Kistler, 1997). Entretanto, a existência de múltiplos grupos de incompatibilidade dentro desta espécie, descoberta por Puhalla \& Spieth (1985), limita a influência de tal mecanismo. Sendo assim, a manutenção da variabilidade genética em $F$. oxysporum requer mecanismos que assegurem alta taxa de mutação (Langin et al., 1995).

Os elementos transponíveis podem ser definidos como seqüências de DNA moderadamente repetitivas que podem mover-se de um local a outro no genoma e, desta maneira, ter um profundo impacto na estrutura e função dos genes, bem como na organização dos cromossomos na espécie (Daboussi, 1997). A descoberta de que são componentes comuns do genoma fúngico, os tornam interessantes em relação ao efeito que exercem no genoma de seus hospedeiros. Eles são responsáveis por grande número de mutações espontâneas, gerando modificações na expressão dos genes, alteração das seqüências de bases e modificações estruturais nos cromossomos (Deschamps et al., 1999; Langin et al., 1995; Hua-Van et al., 1998, 2000, 2001a).

Elementos transponíveis são divididos em duas classes de acordo com o modo de transposição. Os elementos da classe I transpõem via RNA intermediário, utilizando a enzima transcriptase reversa, e os elementos da classe II transpõem diretamente de DNA para DNA (Finnegan, 1989). As subdivisões das classes I e II em subclasses, superfamílias, famílias e subfamílias são estabelecidas segundo características estruturais do elemento e da seqüência de aminoácidos das proteínas codificadas por genes presentes no elemento.

Dentre os elementos transponíveis autônomos já identificados, alguns são muito pertinentes para o uso como ferramentas genéticas. Um dos exemplos é o elemento impala de F. oxysporum (Daboussi, 1997). O primeiro elemento impala foi identificado como uma inserção no gene nia $\mathrm{D}$, que codifica a enzima nitrato redutase, de Aspergillus nidulans (Eidam) Winter, que fora previamente introduzido na linhagem FOM24 de F. oxysporum f. sp. melonis Snyder \& Hansen. Esse elemento tem 1280 nucleotídeos e é constituído por uma região central com uma única sequiência aberta de leitura, sem íntrons, que codifica uma transposase com 340 aminoácidos, flanqueada por repetições terminais invertidas de 27 pares de bases (Langin et al., 1995). O elemento transpõe pelo mecanismo conservativo, tendo como sítio-alvo o dinucleotídeo TA. Cinco subfamílias denominadas D, E, F, $\mathrm{K}$ e $\mathrm{P}$ foram detectadas em $F$. oxysporum. As subfamílias D, $\mathrm{E}$ e $\mathrm{F}$ foram representadas por cópias autônomas, inativas ou truncadas e as subfamílias K e P por elementos inativos. Estas subfamílias diferem entre si por cerca de 20 a $30 \%$ nas sequiências de nucleotídeos (Hua-Van et al., 2001a).

Chiochetti et al. (1999) demonstraram que a distribuição dos elementos transponíveis Fot1 e impala em isolados de F. oxysporum f. sp. dianthi Snyder \& Hansen das raças 1, 2, 4 e 8 são semelhantes nos isolados pertencentes à mesma raça e três grupos foram detectados baseados nessa distribuição. Oligonucleotídeos específicos foram desenhados para amplificar as regiões em que os transposons estavam inseridos e estes foram usados para detecção do patógeno no tecido da planta infetada, já que geraram fragmentos de DNA correspondentes às raças.

Elementos transponíveis atuam como mutagênicos insercionais, e os genes mutados podem ser clonados com facilidade. Essa abordagem tem sido utilizada em plantas e em fungos, desde que as cópias autônomas do elemento já tenham sido clonadas (Daboussi, 1996). Como demonstrado por Migheli et al. (2000), mutantes de patogenicidade em $F$. oxysporum f. sp. melonis foram recuperados depois do evento de transposição do elemento impala. Estes mutantes têm grande potencial para descoberta de genes que codificam determinantes de patogenicidade.

Hua-Van et al. (2001a), analisando a distribuição de impala em isolados não-patogênicos e de diferentes formae speciales de F. oxysporum por meio de hibridização e reação em cadeia de polimerase (PCR), verificaram que impala esteve presente na maioria dos isolados. A identificação de elementos que tenham a mesma sequiência ou posição genômica em diferentes isolados também foi descrita, possibilitando o uso de impala como marcador para estabelecer as relações genéticas dentro de $F$. oxysporum. Esta é outra aplicação dos elementos transponíveis já que, do ponto de vista epidemiológico, é importante definir grupos geneticamente relacionados para o estudo da biologia da população de patógenos de planta (Kistler et al., 1991).

Este trabalho teve como objetivo analisar a distribuição do elemento impala, de acordo com o padrão de hibridização e amplificação por PCR, em diferentes isolados patogênicos e não-patogênicos de $F$. oxysporum.

\section{MATERIAL E MÉTODOS}

\section{Microrganismo e condições de cultivo}

Foram utilizados isolados do fungo $F$. oxysporum nãopatogênicos e F. oxysporum f. sp. phaseoli Kendr. \& Snyder causador de murcha de feijoeiro, cedidos pelo prof. Dr. Everaldo Gonçalves de Barros, do Departamento de Biologia Geral da Universidade Federal de Viçosa, BIOAGRO - Viçosa - MG, pela Empresa Brasileira de Pesquisa Agropecuária EMBRAPA, Centro Nacional de Pesquisa de Arroz e Feijão Santo Antônio de Goiás-GO, e isolados pertencentes à coleção do Departamento de Fitopatologia da Universidade Federal de Viçosa - Viçosa - MG (Tabela 1).

Os isolados foram cultivados por quatro dias, a $28^{\circ} \mathrm{C}$, em placas de Petri contendo meio BDA (Oxoid) enriquecido (1,5 g de caseína hidrolisada, 2,0 g de extrato de levedura e $2,0 \mathrm{~g}$ de peptona por litro, $\mathrm{pH} 6,8$ ).

\section{Extração de DNA total}

Após quatro dias de crescimento, alíquotas de $250 \mu \mathrm{l}$ 
de uma suspensão de conídios, preparadas em Tween-80 $(0,1 \%)$, foram espalhadas em placas com BDA enriquecido coberto com papel celofane. Após 72 h de crescimento, o micélio foi recolhido da superfície do papel celofane com o auxílio de uma espátula e congelado em nitrogênio líquido. A extração de DNA total realizada de acordo com Speacht et al. (1982).

\section{Reação em Cadeia de Polimerase - PCR}

A PCR foi realizada com 20 ng de DNA total em Tris$\mathrm{HCl}(\mathrm{pH} 8,3) 50 \mathrm{mM}, \mathrm{MgCl}_{2} 2,5 \mathrm{mM}, 200 \mathrm{ìM}$ de cada desoxinucleosídeos trifosfatados, $0,5 \mathrm{i} \mathrm{M}$ de cada oligonucleotídeo, 1 unidade de Taq DNA polimerase (Promega) para um volume final de 25 ìl. Os oligonucleotídeos específicos para as subfamílias D e E de impala foram, respectivamente, SPD5 (5' AAGGGCTTACGCACTCACAG 3'), SPD3 (5' CACGG GCAGTGTGAACAGAC 3'), SPE5 (5' AGAACACAACCC TGCCACGG 3') e SPE3 (5' TCCGGGCCGTATGCACAG AG 3') (Hua-Van et al., 2000). O controle negativo utilizando DNA total de Penicillium griseoroseum Dierckx foi incluído em todas as reações. As amplificações foram feitas em um termociclador PTC-100 MJ Research, Inc., programado para 30 ciclos, sendo cada ciclo constituído de um passo a $92{ }^{\circ} \mathrm{C}$ por $60 \mathrm{~s}$, um passo a $60^{\circ} \mathrm{C}$ por $30 \mathrm{~s} \mathrm{e} \mathrm{um} \mathrm{a} 72^{\circ} \mathrm{C}$ por $90 \mathrm{~s}$. Ao final seguiu-se uma etapa extra de alongamento $(10 \mathrm{~min}$, a $72{ }^{\circ} \mathrm{C}$ ). Os produtos de amplificação foram analisados por eletroforese em gel de agarose $1,2 \%$.

\section{Análise por hibridização}

Aproximadamente 3 ìg de DNA total foi clivado com a endonuclease de restrição EcoRI (Promega). Esta enzima foi escolhida por não possuir sítios de restrição na seqüência do elemento transponível impala. Os fragmentos de DNA foram separados em gel de agarose $0,8 \%$, transferidos para uma membrana de náilon (Stratagene, Duralon-UV ${ }^{\mathrm{TM}}$ Membranes) e fixados por exposição à luz ultravioleta (Sambrook et al., 1989). Como sonda, foi utilizado um fragmento de DNA de 572 pares de bases, correspondente ao elemento transponível impala, obtido do plasmídeo pNI160 (Hua-Van et al., 2001b) a partir de uma reação de PCR. O fragmento de DNA foi purificado usando o Kit GFX ${ }^{\mathrm{TM}}$ PCR DNA and Gel Band Purification (Amershan Biosciences) e $500 \mathrm{ng}$ foi marcado por $20 \mathrm{~h}$ com á- ${ }^{32} \mathrm{P}$ (dATP), utilizando-se o Kit Prime It II (Stratagene). As condições de hibridização foram realizadas de acordo com Sambrook et al. (1989). As membranas foram submetidas à auto-radiografia com filmes Kodak X-OTMATIC K por 30 min.

\section{RESULTADOS E DISCUSSÃO}

\section{Distribuição do elemento transponível impala por PCR}

Amostras de DNA de 20 isolados de $F$. oxysporum não-patogênicos e patogênicos ao feijoeiro foram amplificadas por PCR para verificar a presença do elemento transponível, usando oligonucleotídeos específicos para as principais subfamílias de impala, D e E. Os pares de oligonucleotídeos
TABELA 1- Isolados de Fusarium oxysporum patogênicos ou não ao feijoeiro (Phaseolus vulgaris)

\begin{tabular}{lll}
\hline \hline Isolado & Origem* & Patogenicidade \\
\hline D2 & DBG - UFV & Patogênico \\
D2/2 & DBG - UFV & Patogênico \\
D2/3 & DBG - UFV & Patogênico \\
Fus1 & DBG - UFV & Patogênico \\
Fus4 & DBG - UFV & Patogênico \\
Las & DBG - UFV & Patogênico \\
Fop53 & EMBRAPA-GO & Patogênico \\
Fop4005 & EMBRAPA-GO & Patogênico \\
Fop46 & EMBRAPA-GO & Patogênico \\
Fop4007 & DBG - UFV & Patogênico \\
Fop59 & EMBRAPA-GO & Patogênico \\
FoBr-H & DFP - UFV & Não-patogênico \\
FoBr-I & DFP - UFV & Não-patogênico \\
Fo1-6 & DFP - UFV & Não-patogênico \\
Fo3-4 & DFP - UFV & Nâo-patogênico \\
Fo5-4 & DFP - UFV & Não-patogênico \\
Fo5-16 & DFP - UFV & Não-patogênico \\
Fo7-18 & DFP - UFV & Não-patogênico \\
Fo10 & DFP - UFV & Nâo-patogênico \\
Fo15-17 & DFP - UFV & Não-patogênico \\
\hline
\end{tabular}

*DBG-UFV: Departamento de Biologia Geral - Universidade Federal de Viçosa, MG. DFP-UFV: Departamento de Fitopatologia - Universidade Federal de Viçosa, MG. EMBRAPA-GO: Empresa Brasileira de Pesquisa Agropecuária, Santo Antônio de Goiás, GO.

SPD e SPE para as subfamílias D e E permitem, respectivamente, a amplificação de fragmentos de 572 pares de bases e 668 pares de bases.

Pela análise de PCR dos isolados patogênicos, verificou-se que na grande maioria, houve detecção de elementos das subfamílias D e E no mesmo genoma, exceto para o isolado Fop 45, que só apresentou fragmento correspondente à subfamília D, e o isolado Fus 4, em que não se detectou nenhum elemento. Uma menor intensidade dos fragmentos amplificados no isolado Fus1, pode ter sido devido à concentração de DNA usada na reação ou menor número de cópias do elemento (Figuras 1A e B). Esses resultados foram diferentes dos observados para isolados não-patogênicos, pois entre eles, poucos apresentaram amplificação para as subfamílias D e E. Nos isolados FoBr-H, FoBr-I e Fo10, foram detectados elementos da subfamília D, e nos isolados Fo5-4 e Fo5-16 foram detectados elementos da subfamília E, sendo que nenhum dos isolados não-patogênicos apresentou ambas subfamílias (Figuras 1C e D)

A ausência de fragmentos de PCR pode ser interpretada como ausência de uma ou ambas as seqüências complementares aos oligonucleotídeos ou de toda a região. Isolados de $F$. oxysporum de diferentes formae speciales, bem como isolados obtidos do solo, foram analisados para verificar a distribuição de impala por Hua-Van et al. (2001a). Além de oligonucleotídeos específicos para as subfamílias D e E, estes autores utilizaram pares de oligonucleotídeos NS para confirmar a ausência ou presença de outra subfamília, pois estes permitem amplificar cópias das cinco subfamílias de 


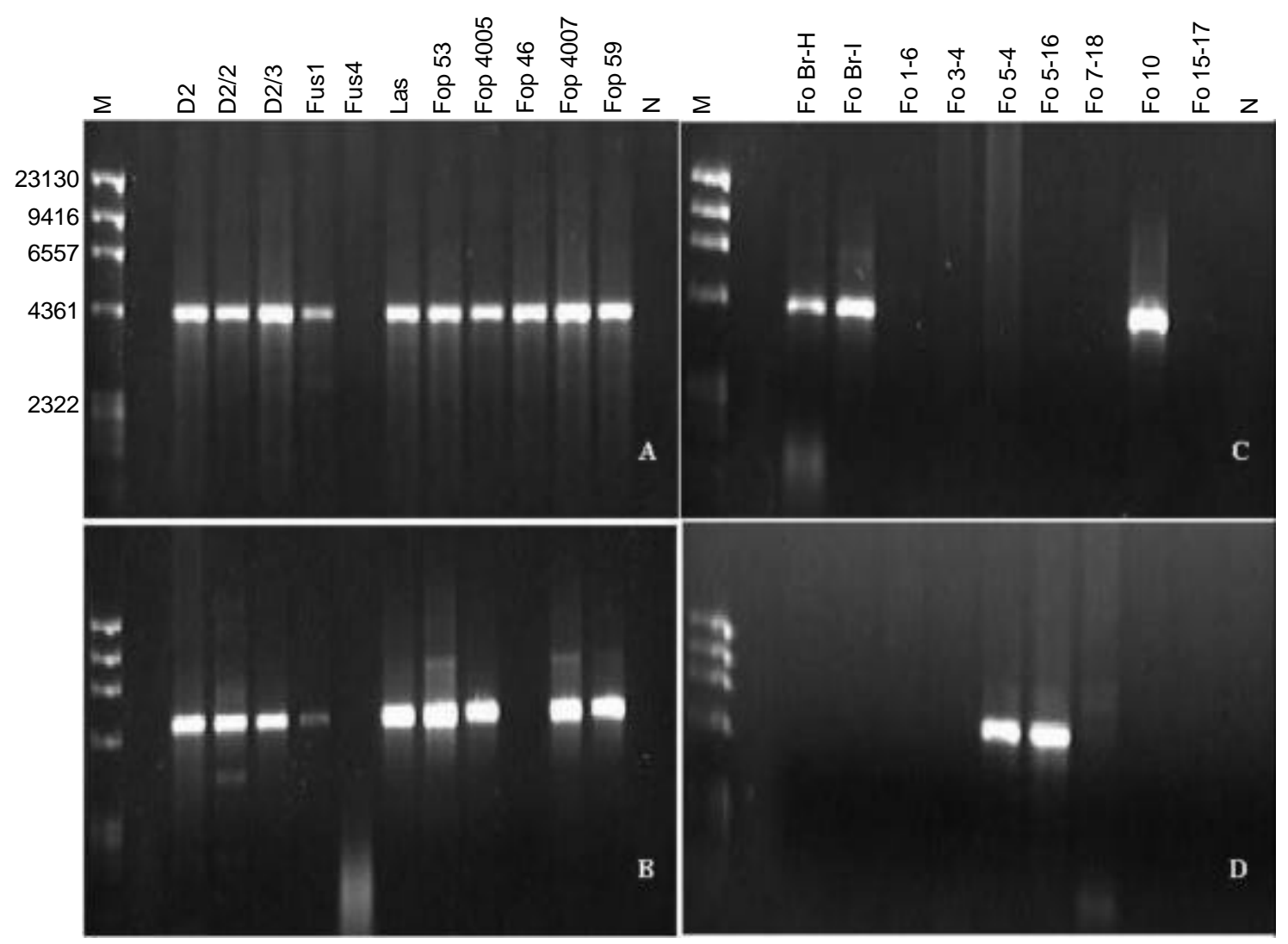

FIG. 1 - Produtos da reação em cadeia de polimerase (PCR) realizada com os pares de oligonucletídeos SpD3 e SpD5 (A e B) e SpE3 e SpE5 (C e D). M corresponde ao DNA do bacteriófago ÖX174 clivado com a enzima HaeIII; os códigos correspondem aos isolados patogênicos (A e C) e não patogênicos (B e D) de Fusarium oxysporum ao feijoeiro (Phaseouls vulgaris) e N corresponde ao controle negativo (Penicilium griseoroseum).

impala. Posteriormente, a clonagem e o seqüênciamento destas cópias permitiram estabelecer as relações filogenéticas entre os isolados. Os dois isolados de $F$. oxysporum $\mathrm{f}$. sp. phaseoli analisados por estes autores puderam ser agrupados filogeneticamente com um isolado não-patogênico originado do solo e com isolados de outras formae speciales, como canariensis e redolens.

De acordo com os resultados da PCR, elementos das subfamílias D e E estão presentes em um mesmo isolado, isto é, dentro do mesmo genoma. Isto confirma a presença de diferentes subfamílias de impala, demonstrando que o mesmo é um antigo componente do genoma de $F$. oxysporum f. sp. phaseoli do Brasil, tendo, possivelmente, uma importante influência na organização do genoma do fungo.

\section{Detecção do número de cópias de impala por hibridização}

A presença do elemento impala foi confirmada por hibridização em 16 isolados, os quais apresentaram de uma a sete cópias de impala. Foi observada variação na intensidade do sinal de hibridização, o que pode indicar a presença de outras subfamílias divergentes no mesmo genoma, como já demonstrado em isolados analisados por hibridização e PCR (Hua-Van et al., 2001a). O número de sinais de hibridização menor ou igual a 7 mostra que impala está presente em baixo número de cópias, sugerindo a ocorrência de seleção no sentido de se eliminar cópias adicionais (Daboussi, 1997; HuaVan et al., 2001a).

Os isolados de $F$. oxysporum f. sp. phaseoli D2, D2/2, D2/3, Las, Fop53, Fop46 e Fop59 apresentaram padrão semelhante, e os isolados Fus1, Fop4005 e Fop4007 apresentaram padrões diversos. O isolado patogênico Fus4 não apresentou nenhum sinal de hibridização (Figura 2), confirmando o resultado de PCR (Figuras 1A e B). Isto indica que este isolado não apresenta cópias endógenas de impala, uma vez que o fragmento usado como sonda é capaz de hibridizar com todas as subfamílias (Hua-Van et al., 2000). Este isolado é um candidato adequado para ser usado em experimentos de mutagênese insercional usando o vetor pNI160, que apresenta uma cópia do elemento impala ativo interrompendo o gene niaD. O isolado Fus1 apresentou menor número de cópias de impala, o que confirma o resultado da menor intensidade do fragmento de DNA na PCR (Figuras $1 \mathrm{~A}$ e $\mathrm{B})$.

O padrão similar dos sinais de hibridização em alguns isolados patogênicos demonstra que estes transposons estão possivelmente inativos. Elementos que perderam a capacidade de transposição são excelentes marcadores genéticos que podem ser usados para a detecção de raças, como 
demonstrado em F. oxysporum f. sp. albedinis Gordon, onde isolados não-patogênicos e de outras formae speciales foram analisados por Fernández et al. (1998). Como os isolados patogênicos apresentaram um padrão de distribuição de Fot 1 muito similar, os sítios de inserção do elemento foram clonados, seqüenciados e a partir destas seqüências foram desenhados oligonucleotídeos que puderam ser utilizados para diagnóstico do patógeno, já que amplificaram um fragmento de DNA específico para $F$. oxysporum f. sp. albedinis. Resultados semelhantes foram descritos por Chiocchetti et al. (1999) para F. oxysporum f. sp. dianthi, que analisaram o padrão de hibridização utilizando como sonda os elementos Fot1 e impala, e observaram um polimorfismo associado às raças fisiológicas, isto é, todos os isolados pertencentes à mesma raça apresentaram perfis idênticos. Oligonucleotídeos específicos, desenhados para amplificar sequiências de DNA de transposons presentes nos isolados, foram usados para detecção de raças deste patógeno nos tecidos da planta infetada.

O resultado da hibridização do DNA de isolados nãopatogênicos é mostrado na Figura 3. Seis isolados apresentaram de 1 a 7 cópias de impala. No caso dos isolados FoBR-H, FoBR-I, Fo10 e os isolados Fo5-4 e Fo5-16 que apresentaram impala da subfamília D e E, respectivamente, pelos experimentos de PCR, foi confirmada a presença de impala pela hibridização. Fo1-6 apresentou 1 cópia de impala, que pode ser de outra subfamília diferente da D e $\mathrm{E}$, pois este isolado não apresentou fragmento de DNA quando oligonucleotídeos para as respectivas subfamílias foram usados na amplificação. É possível também que o elemento possua deleções e não apresente sítios para o anelamento dos oligonucleotídeos. No trabalho de Hua-Van et al. (2001a), os isolados de F. oxysporum que não apresentaram fragmentos de DNA amplificados com os oligonucleotídeos das subfamílias D e E, a hibridização confirmou a presença de impala e o sequenciamento mostrou que eram cópias de outras subfamílias.

Nos isolados não-patogênicos o padrão de hibridização detectado foi variável, refletindo posições genômicas diferentes (Figura 3). No entanto, o número de isolados que apresentaram impala foi menor do que o observado para os patogênicos (Figura 2). Esta maior diversidade do padrão de hibridização dentro dos isolados não-patogênicos é explicável pelo fato de que como ocorrem em solos diversos, as características de crescimento em diferentes substratos e particularidades ecológicas são variáveis, esta capacidade de adaptação a várias condições ambientais pode estar relacionada a uma aptidão particular para modificações genéticas geradas pelos elementos transponíveis (Edel et al., 2001)

A distribuição da família impala dentro dos isolados analisados, tanto por PCR, quanto por hibridização, mostrou que elementos impala estão presentes na maioria dos isolados analisados e que $F$. oxysporum é bastante heterogêneo, como demonstrado por outros marcadores moleculares (Woo et al., 1996).

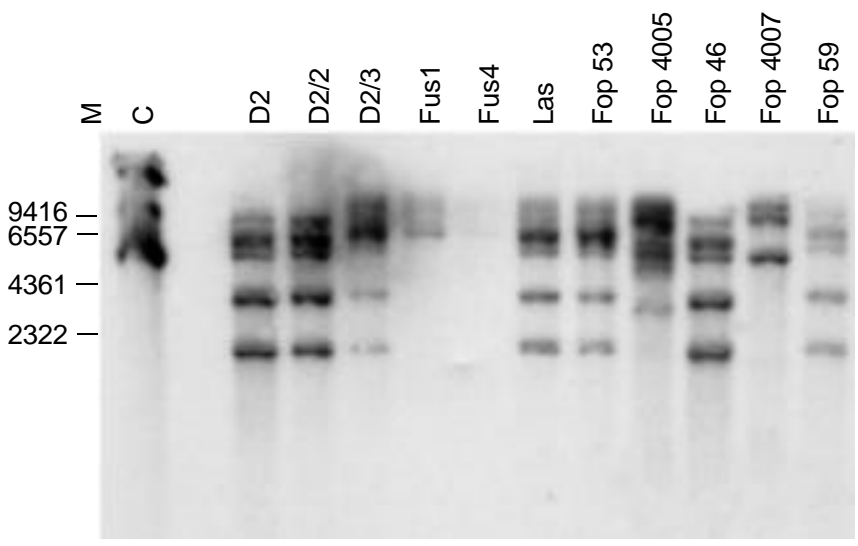

FIG. 2 - DNA dos isolados patogênicos de Fusarium oxysporum ao feijoeiro (Phaseolus vulgaris), clivados com a enzima EcoRI e hibridizados com um fragmento de DNA de $572 \mathrm{pb}$ de impala. (M) DNA do fago lambda clivado com HindIII e (C) controle positivo pNI160.

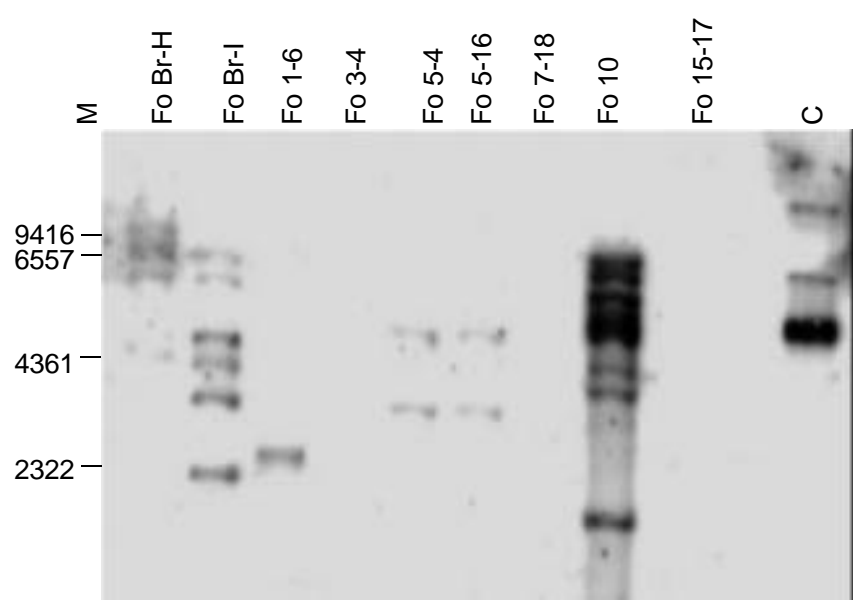

FIG. 3 - DNA dos isolados não-patogênicos de Fusarium oxysporum ao feijoeiro (Phaseolus vulgaris), clivados com a enzima EcoRI e hibridizados com um fragmento de DNA de $572 \mathrm{pb}$ de impala. (M) DNA do fago lambda clivado com HindIII e (C) controle positivo pNI160.

\section{AGRADECIMENTOS}

Somos gratos ao apoio financeiro das agências brasileiras CAPES (Coordenação de Aperfeiçoamento de Pessoal de Nível Superior), FAPEMIG (Fundação de Apoio a Pesquisa do Estado de Minas Gerais) e CNPq (Conselho Nacional de Desenvolvimento Científico e Tecnológico) e ao Prof. Dr. Everaldo G. de Barros e à EMBRAPA (Empresa Brasileira de Pesquisa Agropecuária) pelos isolados de $F$. oxysporum cedidos.

\section{REFERÊNCIAS BIBLIOGRÁFICAS}

ALVES-SANTOS, F.M., BENITO, E.P., ESIAVA, A.P. \& DIASMINGUEZ, J.M. Genetic diversity of Fusarium oxysporum strains 
from common bean fields in Spain. Applied and Environmental Microbiology 65:3335-3340. 1999.

CHIOCCHETTI, A., BERNARDO, I., DABOUSSI, M.J., GARIBALDI, A., LODOVICA GULLINO, M., LANGIN, T. \& MIGHELI, Q. Detection of Fusarium oxysporum f. sp. dianthi in carnation tissue by PCR amplification of transposon insertions. Phytopathology 89:1169-1175. 1999.

DABOUSSI, M.J. Fungal elements transposable: generators of diversity and genetic tools. Journal of Genetic 75:325-339. 1996.

DABOUSSI, M.J. Fungal transposable elements and genome evolution. Genetica 100:253-260. 1997.

DESCHAMPS, F., LANGIN, T., MAURER, P., GERLINGER, C., FELENBOK, B. \& DABOUSSI, M.J. Specific expression of the Fusarium transposon Fot1 and effects on target gene transcription. Molecular Microbiology 31:1373-1383. 1999.

EDEL, V., STEINBERG, C., GAUTHERON, N., RECORBET, G. \& ALABOUVETTE, C. Genetic diversity of Fusarium oxysporum populations isolated from different soils in France. FEMS Microbiology Ecology 36:61-71. 2001.

FERNÁNDEZ, D., OUITEN, M., TANTAQUI, A., GEIGER, J.P., DABOUSSI, M.J. \& LANGIN, T. Fot1 Insertions in the Fusarium oxysporum f. sp. albedinis genome provide diagnostic PCR targets for detection of the date palm pathogen. Applied and Enviromental Microbiology 64:633-636. 1998.

FINNEGAN, D.J. Eukariotic transposable elements and evolution genome. Trends Genetics 5:103-107. 1989.

GORDON, T.R. \& MARTYN, R.D. The evolutionary biology of Fusarium oxysporum. Annual Review of Phytopathology 35:111128. 1997.

GORDON, T.R. \& OKAMOTO, D. Population structure and relationship between pathogenic and nonpathogenic strains of Fusarium oxysporum. Phytopathology 82:73-77. 1992.

HUA-VAN, A., DAVIERE, J.M., KAPER, F., LANGIN, T. \& BABOUSSI, M.J. Genome organization in Fusarium oxysporum: clusters of class II transposons. Currents Genetics 37:339-347. 2000.

HUA-VAN, A., HERICOURT, F., CAPY, P., DABOUSSI, M.J. \& LANGIN, T. Three highly divergent subfamilies of the impala transposable element coexist in the genome of the fungus Fusarium oxysporum. Molecular and General Genetics 259:354-362. 1998.

HUA-VAN, A., LANGIN, T. \& DABOUSSI, M.J. Evolutionary history of the impala transposon in Fusarium oxysporum. Molecular Biology and Evolution 18:1959-1969. 2001a.

HUA-VAN, A., PAMPHILE, J.A., LANGIN, T. \& DABOUSSI, M.J. Transposition fo autonomous and engineered impala transposons in Fusarium oxysporum and a related species. Molecular and General Genetics 264:724-731. 2001b.

KISTLER, H.C. Genetic diversity in the plant-pathogenic fungus Fusarium oxysporum. Population Genetics of Soilborne Fungal Plant Pathogens 87:474-479. 1997.

KISTLER, H.C; MOMOL, E.A. \& BENNY, U. Repetitive genomic sequences for determining relatedness among strains of Fusarium oxysporum. Phytopathology 81:331-336. 1991.

LANGIN, T., CAPY, C. \& DABOUSSI, M.J. The transposable element impala, a fungal member of the Tc1-mariner superfamily. Molecular and General Genetics 246:19-28. 1995.

MIGHELI, Q., STEINBERG, C., DAVIERE, J.M.; OLIVAIN, C., GERLINGER, C., GAUTHERON, N., ALABOUVETTE, C. \& DABOUSSI, M.J. Recovery of mutants impaired in pathogenicity after transposition of impala in Fusarium oxysporum f. sp. melonis. Phytopathology 90:1279-1284. 2000.

PUHALLA, J.E. \& SPIETH, P.T. A comparison of heterokaryosis and vegetative incompatibility among varieties of Gibberella fujikuroi (Fusarium moniliforme). Experimental Mycology 9:39-47. 1985.

SAMBROOK, J., FRITSCH, E. F. \& MANIATIS, T. Molecular cloning: a laboratory manual. $2^{\text {nd }}$ ed. New York. Cold Spring Harbor Laboratory. 1989.

SNYDER, W.C. \& HANSEN, H.N. The species concept in Fusarium. American Journal of Botany 27:64-67. 1940.

SPEACHT, C.A., DIRUSO, C.C., NOVOTNY, C.P. \& ULLRICH, R.C.A. A method for extracting high molecular weight desoxyribonucleic acid from fungi. Annual Review of Biochemistry 119:158-163. 1982.

WOLLENWEBER, H.W. \& REINKING, O.A. Die Fusarien. Ihre Beschreibung. Schadwirkung and Bekampfung. Berlin: Paul Parey. 1935.

WOO, S.L., ZOINA, A., DEL SORBO, G., LORITO, M., NANNI, B., SCALA, F. \& NOVIELLO, C. Characterization of Fusarium oxysporum f. sp. phaseoli by pathogenic races, VCGs, RFLPs and RAPD. Phytopathology 86:966-973. 1996. 